\title{
BILOGÍA FÍLMICA MACHADIANA: LA SOMBRA DE CAÍN SOBRE LA ;HERMOSA TIERRA DE ESPAÑA!
}

MACHADIAN FILM BILOGY:

THE SOMBRA DE CAÍN ON THE ¡HERMOSA TIERRA DE ESPAÑA!

\author{
Fernando GÓMEZ BECEIRO \\ Universidad de Santiago de Compostela \\ fgbeceiro@gmail.com \\ Natalia ALONSO RAMOS \\ Universidad de Santiago de Compostela \\ natalia.alonso@usc.es \\ José Luis CASTRO DE PAZ \\ Universidad de Santiago de Compostela \\ joseluis.castro@usc.es
}

Resumen: Ya superado el octogésimo aniversario del fallecimiento de Antonio Machado, volvemos nuestra mirada hacia dos películas cuyos discursos gravitan sobre una honda inmersión en su obra y su personalidad. Dirigidas por Arturo Ruiz-Castillo entre el verano de 1952 y la primavera de 1953, La laguna negra surge como transposición de un romance del poeta sevillano, mientras que el relato posbélico de Dos caminos parece nutrirse de una tupida invocación alegórica del pensamiento machadiano. Escasamente conocidos y apenas considerados por la historiografía cinematográfica, ambos filmes conforman una inconfesa bilogía dotada de una insólita densidad semántica que urge reivindicar.

Palabras clave: Antonio Machado. Arturo Ruiz-Castillo. La laguna negra. Dos caminos. Cine español posbélico. Exilio. Cainismo. 


\begin{abstract}
Just after the eightieth anniversary of death of Antonio Machado, we turn our attention to two films whose speeches gravitate a deep immersion in his work and his personality. Directed by Arturo RuizCastillo between the summer of 1952 and the spring of 1953, La laguna negra emerges as transposition of a romance of the Sevillian poet, while the post-war account Dos caminos seem to be nourished by a dense allegorical invocation of Machadian thought. Scarcely known and barely considered by historiography film, both films make up an unmistakable biology with an unusual semantic density that needs to be vindicated urgently.
\end{abstract}

Key Words: Antonio Machado. Arturo Ruiz-Castillo. La laguna negra. Dos caminos. Post-war Spanish Cinema. Exile. Fratricide.

\title{
1. EXORDIO. ¡HERMOSA TIERRA DE ESPAÑA!
}

Un largo travelling se desliza por el estremecedor campo de internamiento improvisado en las playas de Argelès-sur-Mer, próximas a Colliure. La cámara recorre pausadamente la multitud de seres desvalidos que se disponen a pernoctar a la intemperie, hacinados sobre la arena. Desde el plano acústico, la alocución que emana de la megafonía ("Las noticias del sur de Francia coinciden en acusar el orden imperfecto con que el ejército leal ha cruzado la frontera española [...] Todo un campamento perfectamente acondicionado acoge en Francia a los soldados de la libertad") constituye la antítesis al dramático tumulto de la muchedumbre, revelando la incapacidad de las autoridades francesas para amparar a la gran diáspora republicana. Al llegar al grupo en que se hallan los personajes principales (el protagonista Miguel [Rubén Rojo] y su compañero de evasión Pedro [Juanjo Menéndez]), el travelling se detiene para mostrar la acción en una sucesión de planos cortos, centrándose en los vanos intentos de Pedro por protegerse del frío mientras replica el falaz discurso recién escuchado. Un plano de conjunto muestra a Miguel tendido sobre la arena junto a un personaje anónimo, de aspecto alicaído, envejecido y acaso enfermizo, tan solo guarecido por su abrigo y una boina castellana que únicamente dejan desprovistas las lívidas facciones de su rostro. El ornamento extradiegético de los primeros acordes musicales comienza a enfatizar la secuencia cuando Miguel se incorpora levemente para exclamar mirando al cielo: 
"iQué limpio cielo! Cuando apriete el sol no vamos a tener ni la sombra de un árbol”. Es entonces cuando el hombre anónimo declama en tono grave $\mathrm{y}$ fatigoso los conocidos versos:

\author{
¡Chopos del camino blanco, álamos de la ribera, \\ espuma de la montaña \\ ante la azul lejanía, \\ sol del día, claro día! \\ ¡Hermosa tierra de España! (Machado, 1999a: 76).
}

Conmovido por el poema y con la mirada perdida en el horizonte,

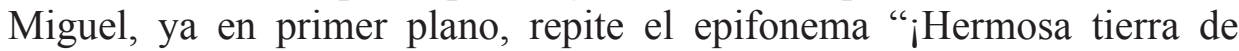
España!”, interesándose a continuación por su identificación (“¿Eso es una copla?"). Un nuevo primer plano, ahora del poeta, refleja su gesto melancólico mientras responde sin apenas inmutarse: "Es un verso que hice una vez”. “Eres poeta?”, pregunta finalmente Pedro; ante lo cual, el autor de "Orillas del Duero" expresa con resignación: "Poeta... Eso creía yo". En sentido inverso al anterior y acompañado ahora de la música que acentúa la patética estampa nocturna, otro extenso travelling vuelve a recorrer el campo de internamiento. El tránsito del ocaso al alba se resuelve en elipsis, remarcada por unos planos generales de la playa iluminada por el sol. De vuelta al lugar donde se desarrolla la acción, un plano de conjunto muestra a Pedro despertando a Miguel para comunicarle que le reclaman por megafonía. Tras ellos, unos personajes observan atemorizados al poeta, que no ofrece síntomas de interrumpir su letargo. Pedro, que hasta ahora no había reparado en ello, trata de desvelarlo en un plano medio de ambos personajes, pero enseguida se percata del trágico desenlace. Una sutil panorámica guiada por la mano de Pedro cubriendo el rostro del difunto corrige el encuadre desplazando a Pedro al fuera de campo y otorgando la totalidad del plano al poeta, cuyo cuerpo yace inerte sobre la arena de Argelès tras soñar con la anhelada tierra de origen, desamparado y rodeado de extraños, víctima del dolor, la soledad y la amargura, y sin ya poder atisbar el sol del claro día. Un golpe solemne de la música subraya el acto. Ha muerto Antonio Machado. 


\section{ESTADO DE LA CUESTIÓN Y PUNTO DE PARTIDA. BILOGÍA MACHADIANA: LA LAGUNA NEGRA (1952) Y DOS CAMINOS (1953)}

Dirigida por el cineasta madrileño Arturo Ruiz-Castillo, a partir de un guion de Clemente Pamplona con diálogos de José Antonio Pérez Torreblanca, Dos caminos aborda las espinosas cuestiones de la posguerra y el exilio narrando las antagónicas vidas de dos antiguos combatientes republicanos cuyos caminos se habían bifurcado al término de la Guerra Civil, traspasando uno la frontera francesa, integrándose el otro en la sociedad posbélica, y que vuelven a confluir años después cuando el primero regresa como guerrillero del maquis. Filmada con no pocas dificultades en los primeros meses de 1953 y estrenada un año después tras un tránsito sorprendentemente exitoso por diversos festivales - Málaga, San Sebastián, Barcelona, Gijón-, el complejo trasfondo ideológico del filme ocasionó una radical disparidad de criterios en los críticos del momento ${ }^{1}$. Ajena a tal divergencia crítica, la historiografía ha tendido en cambio a esbozar una percepción casi unánime - salvo muy contadas excepciones - en torno a la supuesta dimensión ejemplarizante de un argumento presuntamente próximo a los intereses gubernamentales, si acaso tan solo detectando la novedosa mirada a la persistencia bélica de los derrotados y los resortes de un didactismo conciliador, por otro lado, afín a las necesidades coyunturales del Régimen.

Imprecisiones históricas al margen, la evocación simbólica de la muerte de Antonio Machado en la secuencia central de Dos caminos -

\footnotetext{
${ }^{1}$ Si en la prensa oficialista - en cabeceras como el diario generalista Arriba o el semanario especializado Primer Plano - contrastan los elogios hacia la presunta exaltación patriótica del filme con las denuncias al trato benevolente dado a los vencidos llegando incluso en ocasiones a calificar la obra como un inadmisible canto republicano, no podemos tampoco dejar de lado el eco suscitado por el novedoso tratamiento del exilio en la militancia clandestina. Así, por ejemplo, en los Cuadernos de Cultura del Partido Comunista de España se incluía un extenso artículo donde, tras una dura crítica sustentada en cuestiones políticas ligadas al supuesto mensaje reaccionario, se acababan destacando en cambio los positivos efectos que la dimensión heroica otorgada al protagonista republicano podía provocar en determinados sectores de la resistencia al franquismo (Díaz, 1954). Asimismo, Díez Puertas recoge un interesantísimo fragmento de una carta de Jorge Semprún a los dirigentes del PCE en el exilio en el que llamaba la atención sobre los valores políticos de Dos caminos: "todas las simpatías del público van hacia el protagonista 'rojo', que es un valiente, un 'idealista'... Muere como un héroe, y frente a él su compañero que eligió quedarse resalta como un pobre cobarde" (2003: 266).
} 
correspondiente a uno sus fragmentos de mayor dramatismo, exactamente en el punto intermedio del discurso - supone un buen indicio de la hondura semántica del relato. Pero, además, dicha inmersión en la personalidad y/o la obra del autor sevillano ya había sido iniciada por el mismo director en su anterior largometraje, La laguna negra. Escrita por Vicente Coello, Ángel A. Jordán y el propio Ruiz-Castillo — también con diálogos de Pérez Torreblanca - a partir de una sinopsis argumental del catedrático Lázaro Montero, realizada en el verano de 1952 y estrenada al cabo de un año con muy discreta acogida (a lo que luego habría que añadir el prolongado desdén historiográfico y analítico hacia una de las escasas manifestaciones fílmicas surgidas de la poesía castellana), la película consistía en efecto en una adaptación del extenso romance La tierra de Alvargonzález, incluido en Campos de Castilla ${ }^{2}$. Ambos filmes conforman de este modo una suerte de inconfesa - y seguramente no deliberada - bilogía cuya sólida cohesión machadiana no podría ser comprendida sin considerar el fecundo acervo intelectual del director y sin sopesar la analogía de dicho bagaje con ciertas constantes del pensamiento del poeta.

Englobado en la Generación de los renovadores (Castro de Paz, 2002 y 2012), hijo del editor José Ruiz-Castillo Franco, educado en el Instituto-Escuela bajo el amparo de la Junta de Ampliación de Estudios y participante activo en diversos movimientos artísticos y culturales de la Segunda República (Gómez Beceiro, 2016), la infancia y juventud de Arturo Ruiz-Castillo estuvieron determinadas por su contacto con las élites intelectuales de la Edad de Plata. Tras una dilatada trayectoria en el documental, su debut en el largometraje comercial se había producido a mediados de los años cuarenta con la adaptación de la novela de Pío Baroja Las inquietudes de Shanti Andía. Años después, y ya en plena madurez creativa, nada se antojaba más idóneo para retomar sus predilectos referentes literarios que la obra de una figura tan próxima y admirada como Antonio Machado, en cuya vasta y diversa herencia cultural intervino con similar trascendencia el decisivo influjo pedagógico que luego experimentaría Ruiz-Castillo.

\footnotetext{
${ }^{2}$ El relato original cuenta en realidad con tres versiones, dos en verso y una en prosa, publicadas en la primera mitad de 1912, siendo la más conocida la versión definitiva del romance difundida por la Editorial Renacimiento dentro de Campos de Castilla (Beceiro, 1994, 2000; Gibson, 2006).
} 


\section{INSTITUCIONISMO, NOVENTAYOCHISMO Y LA ESENCIALIDAD CASTELLANA EN LA LAGUNA NEGRA}

Es sobradamente conocido que el descubrimiento de la tierra soriana causó tal impacto en la vida de Antonio Machado que acabaría orientando su obra hacia nuevos derroteros "desde las oscuras galerías del alma, al mundo exterior" (González, 1986: 28), de tal modo que a partir de entonces "[1] os universales del sentimiento y del sueño han de ceder su interés a la esencialidad castellana o andaluza, a la peculiaridad del alma popular o a la meditación sobre el ser, el amor y la muerte" (Beceiro, 1975: 116). Dicho viraje a la esencialidad castellana perpetrado en Campos de Castilla ha sido además señalado como el inicio de la dimensión crítica-social que ubica al autor dentro de los contornos generacionales noventayochistas, tomando al paisaje como "símbolo del alma interior de Castilla, y a través de ella, de España” (Cerezo Galán, 1975: 510). En cualquier caso, lo más significativo para nuestro discurso es el hecho de que esa sustancial deriva hacia la Generación del 98 responde en gran parte a la vivificación de la decisiva veta cultural institucionista heredada por el autor:

El sedimento ético, patriótico y regeneracionista que la Institución Libre de Enseñanza había dejado en su espíritu, se reactiva al contacto con la triste realidad española que Soria representaba y a la que él, entre el París simbolista y el Madrid bohemio, tal vez había vivido ajeno (González, 1986: 29).

Descendiente de una línea familiar muy cercana al ámbito fundacional de la ILE de la que fue alumno en sus primeras promociones, la determinante influencia de dicha experiencia pedagógica en la vida y obra de Antonio Machado ha sido frecuente motivo de estudio y reivindicación. Pero, de entre todo ese pluridimensional influjo krausoinstitucionista, interesa destacar ahora dos aspectos que guardan entre sí una íntima relación y que entroncan además con los ya referidos perímetros noventayochistas: la estimación del paisaje y el interés por el folclore y las tradiciones populares. Ambas cuestiones se hallan además estrechamente ligadas a un fenómeno que ocupó un destacadísimo lugar dentro del referido programa pedagógico: la práctica del excursionismo, que acabaría por convertirse en una de las principales aficiones del poeta (Torres López, 
1990: 515) y en elemento puntal de su método creativo (Vila-Belda, 2006: 219). Las conocidas declaraciones del propio Antonio Machado son fiel reflejo de ello:

Soy hombre extraordinariamente sensible al lugar en que vivo. La geografia, las tradiciones, las costumbres de las poblaciones por donde paso, me impresionan profundamente y dejan huella en mi espiritu. Allá, en 1907, fui destinado como catedrático a Soria. Soria es lugar rico en tradiciones poéticas. Allí nace el Duero, que tanto papel juega en nuestra historia. Alli, entre San Esteban de Gormaz y Medinacelli, se produjo el monumento literario del Poema del Cid. Por si ello fuera poco, guardo de alli recuerdo de mi breve matrimonio con una mujer a la que adoré con pasión y que la muerte me arrebató al poco tiempo. Y viví y sentí aquel ambiente con toda intensidad. Subí al Urbión, al nacimiento del Duero. Hice excursiones a Salas, escenario de la trágica leyenda de los Infantes. $Y$ de alli nació el poema de Alvargonzález (Machado, 1999b: 301-302).

En efecto, como es sabido La tierra de Alvargonzález surgió de una expedición por los Picos de Urbión realizada tras el verano de 1910. Muchos de los parajes del itinerario acabarían formando parte del enclave espacial del romance; pero, además, la menos difundida versión en prosa comienza incluso con una introducción en la que se ofrece una simulación de veracidad argumental, al poner el relato en boca de un campesino que el autor conoce en un viaje por la sierra, fingiendo así ser un mero transmisor de una leyenda de anónima autoría. Con todo, es en la más conocida versión poética donde se percibe con mayor claridad ese apego por la tradición colectiva mediante la propia adopción de la forma romancística, tal como constató el autor en su prólogo a Campos de Castilla:

[P]ensé que la misión de los poetas era inventar nuevas historias de lo eterno humano, historias animadas que, siendo suyas, viviesen no obstante por sí mismas. Me pareció el romance la suprema expresión de la poesía y quise escribir un nuevo Romancero. A este propósito responde 'La tierra de Alvargonzález' (Machado, 1999b: 79).

Además, el trasfondo de la historia, truculento y decadente, se desvía de las gestas heroicas cantadas por el romance tradicional para "presenta[r] una clara voluntad de dignificar cierta veta del romancero 'vulgar'" (Riva, 2009: 45). Como sintetiza García Mateos (1990: 413), 
"[e]l romance machadiano [...] nace del pueblo y de la tierra donde se escucharon sus historias de honda tragedia. Y se acerca el poeta a la rama más popular del Romancero: la de los romances de ciego y pliegos de cordel". Y así concluía Machado:

\begin{abstract}
Muy lejos estaba yo de pretender resucitar el género en su sentido tradicional. La confección de nuevos romances viejos - caballerescos o moriscos - no fue nunca de mi agrado, y toda simulación de arcaísmo me parece ridícula. Cierto que yo aprendí a leer en el Romancero General que compiló mi buen tío don Agustín Durán; pero mis romances no emanan de las heroicas gestas, sino del pueblo que las compuso y de la tierra donde se cantaron; mis romances miran a lo elemental humano, al campo de Castilla y al Libro Primero de Moisés, llamado Génesis (Machado, 1999b: 79).
\end{abstract}

Filmada la mayor parte de la película en las inmediaciones de esa Sierra de Urbión que sirvió de inspiración a $\mathrm{Machado}^{3}$, considerando el denso poso que la formación institucionista fraguó en el pensamiento de Ruiz-Castillo ${ }^{4}$ se podrá intuir fácilmente que un semejante estímulo al que provocó la tierra soriana en Machado debió de suscitar en el cineasta su aproximación al poeta que llegaría a ser calificado como "la voz lírica de la Institución" (Jiménez-Landi, 1993: 270); y, a través de él, a Castilla, sus costumbres, sus leyendas, los ecos de su pasado, su paisaje mesetario de las riberas del Duero y el agreste serrano.

Así pues, si el argumento del poema original se resume en el desarrollo de "dos pilares básicos: el crimen, con sus antecedentes materiales y espirituales, y el castigo, con sus alternativas y factores retardantes" (Beceiro, 1994: 420) en una "historia brutal y desgarrada, de crímenes horrendos y maldiciones bíblicas" (Alvar, 1997: 38), el conjunto de operaciones efectuadas por los guionistas en la traslación del romance a la pantalla consiste en la adopción del núcleo del relato (la idea de la codicia representada en los actos de dos hermanos, Martín [José María

\footnotetext{
${ }^{3}$ Aunque para las imágenes correspondientes a La laguna negra el director decidió sustituir las fuentes del Duero por otro enclave castellano por él muy conocido fruto de su propia faceta excursionista: la Laguna grande de Gredos, en la provincia de Ávila.

${ }^{4}$ Cuestión a la que el director dedica abundante espacio en su manuscrito autobiográfico inédito custodiado por la Residencia de Estudiantes, donde de hecho llega a referirse a su paso por el Instituto-Escuela junto a sus hermanos como "lo más importante que nos ocurrió y que nos marcaría para siempre en nuestro modo de ser, de vivir y de pensar" (Ruiz-Castillo, s.f.).
} 
Lado] y Juan [Tomás Blanco], asesinando a su padre por el afán de heredar su hacienda), despojándolo de algunas cuestiones accesorias que se alejan del conflicto esencial (la historia previa del padre, la figura de la madre e incluso el propio nombre de Alvargonzález) y agregando nuevos elementos fundamentales en el transcurso dramático. Nos referimos principalmente, al margen de numerosos aspectos secundarios, a las esposas antagónicas de los parricidas, Ángela (María Jesús Valdés) — mujer de Juan, bondadosa, ingenua, desvinculada de las artimañas del crimen, y en torno a la cual se esbozará una leve y supletoria subtrama melodramática que precipitará el desenlace- y Candelas (Maruchi Fresno) - esposa de Martín, perversa, maquiavélica y dominante, y en quien recae la mayor culpabilidad al ser ella quien incita las viles acciones de su cónyuge y su cuñado-. Asimismo, se introduce también una modificación del desenlace con el frustrado intento de asesinato del tercer hijo, Miguel (Fernando Rey) - que regresa de las Américas al enterarse de la muerte del padre - y que está a medio camino entre las diferentes versiones del relato original ${ }^{5}$.

\subsection{Costumbrismo y mito}

Una composición de diversos enseres domésticos —un botijo, unas jarras, una cazuela y unas cuerdas sobre la mesa - dispuestos a modo de bodegón sirve de estampa ilustrativa de unos créditos acompañados por una música solemne que cesa bruscamente para dar paso al rítmico repiqueteo de unas campanas - en señal de duelo ante el horrendo crimen recién cometido pero que todavía desconocemos - mientras un breve rótulo introduce la historia: 'La 'laguna negra' está en Castilla pero esta historia pudo suceder en cualquier lugar del mundo. Es la eterna tragedia de la codicia". Acto seguido, y sin transición alguna, un desplazamiento panorámico hacia la derecha conduce a una conjugación de travelling y panorámica laterales y descriptivos sobre el típico caserón castellano, desde la escalera central sobre la que una puerta se abre misteriosamente hasta el sillón vacío del patriarca ubicado junto al hogar extinto. La voz en off cadavérica del padre comienza entonces a entonar un sermón, lamentando

\footnotetext{
${ }^{5}$ Pues si en el romance en verso no figura el fratricidio, la versión en prosa es más trágica al ser Miguel asesinado por sus hermanos. En la película, Candelas persuade a Martín de matar a Miguel para heredar toda la hacienda y por el temor a que éste se entere de lo sucedido, pero el homicidio resulta frustrado, pereciendo Martín y Juan en la tentativa.
} 
el vil suceso y profetizando la maldición que se cernirá sobre la familia, y que a lo largo de toda la secuencia irá de la mano de un prolongado crescendo musical que se superpone al repicar de las campanas:

El daño que hacéis, hijos míos, al darme la muerte es dejar vacio para
siempre el hogar donde yo os di la vida. No podréis sentaros tranquilos
en mi puesto. No tendréis hijos que os hereden después de daros ternura
y obediencia. Vuestras manos se avergonzarán malditas al partir el pan
sobre la mesa de vuestros mayores. Jamás acudirá la abundancia a vuestros
manteles y no caerá la bendición de Dios sobre vuestra fatiga iCómo, hijos
míos, os dejasteis ganar por la codicia para quitarme con la vida lo que yo
gané y conservé pensando en vosotros! Pero bien pronto estaréis frente a
vuestro castigo. La tierra se hará polvo seco en vuestras manos. Entrará la
plaga en el redil y en las paneras. Y cada día, cuando vayáis a buscar esos
campos que ambicionáis y que nunca serán vuestros os hará daño la luz de
los cielos, y el viento os dirá mi nombre sin descanso, y los árboles y hasta
las piedras estarán murmurando a vuestro paso el horror de mi sangre en
esta laguna negra.

Mediante un fundido-encadenado (de aquí en adelante todas las transiciones de la secuencia serán resueltas mediante encadenados en aras de la continuidad del crescendo, musical y visual), la cámara se sitúa en la posición del sillón vacante adoptando el punto de vista del espíritu, para completar una panorámica circular inversa sobre toda la estancia, dando paso a un travelling desde el suelo hasta el gran portalón que se abre lentamente: el espíritu que se levanta y alza su / nuestra mirada para acceder al exterior. Continuando la prédica, un siguiente travelling, picado y oblicuo, a través de los campos del Duero, conduce río arriba a la espantosa Laguna Negra, con sus aguas todavía ondeantes. El siguiente plano - al cual se accede ahora por corte tras los encadenados previosmuestra a los parricidas, Martín y Juan, observando la laguna de espaldas a la cámara, hasta que el primero de ellos desaparece dejando solo a Juan, que mira sus letales manos, tomadas en plano detalle seguido de un primer plano del criminal dirigiendo su mirada hacia el fuera de campo mientras escucha la voz espectral que convoca a sus hijos.

Como vemos, la secuencia inicial resulta sumamente representativa de un discurso que aúna los resortes costumbristas y míticos del drama rural. Si la imagen del bodegón, así como las panorámicas que describen al detalle la casa labriega castellana, demuestran el esmero por aferrar el 
texto en las matrices agrarias, dicho empaque costumbrista ejerce como pedestal sobre el que se erigen los cimientos de un drama que oscila entre ese arquetípico entorno rural de raíz legendaria y el aura mítica de un relato alegórico cuyas huellas se remontan a narraciones de ancestral arraigo en la cultura occidental, mediante la presencia de numerosas apelaciones al más elemental planteamiento de una trama estrictamente ceñida al castigo de los criminales. En este sentido, si ese mismo bodegón constituye además una síntesis de los pilares del relato (el crimen: la cuerda que sirve para fondear al muerto en la laguna; y el castigo: los recipientes vacíos por la escasez presagiada), concurren asimismo en el fragmento otros rasgos retóricos que serán recurrentes en todo el texto como recordatorio de los sucesos e indicios de la punición (los luctuosos compases de las campanas, el trono desierto del padre...). En cualquier caso, todo ello alcanza su mayor énfasis con el sermón del espectro, que al amonestar a sus hijos por sus actos y profetizar la maldición semeja adoptar un tono sobrehumano como un ente superior, omnipotente y todopoderoso - una deidad, un padre - que desata su ira sobre las criaturas terrenales - sus siervos, sus hijos- que osaron alzarse contra él tentados por los vicios concupiscibles de la codicia. El motivo del crimen y castigo parece estar forjado así sobre un fondo primigenio que emana de los relatos bíblicos. Es pues esa confluencia entre el ambiente costumbrista y el carácter universal y eterno de la tragedia, entre lo específico y lo cósmico (conjunción ya advertida por el rótulo que deja constancia del asentamiento en tierras castellanas, pero apuntando igualmente la universalidad de un hecho que pudiera suceder en cualquier lugar del mundo), la que ancla el texto en el seno de esa gran corriente de estilización del cine español que Santos Zunzunegui (2002) definió como la vía del mito.

Más destacable que la propia línea argumental es la atmósfera lúgubre y pavorosa, por momentos grotesca, que confiere un tono permanentemente acechante a un relato en el que los roles de los diferentes personajes principales — sus atributos y sus pulsiones - resultarán cada vez más definidos (el padecimiento de Ángela, el empecinamiento de Martín, y, sobre todo, la perversidad desenfrenada de Candelas - cuyo odio e histeria abastecen con creciente ímpetu la fuerza motriz del maly el arrepentimiento de Juan — en quién parece recaer todo el peso de la conciencia-), radicalizándose y avivando un estado de gradual ebullición que culminará con la crispación enajenada de la devastadora apoteosis 
final. La prospección de las simas psíquicas de los turbados protagonistas en sostenidos primeros planos y pronunciados ángulos de cámara, y la captación del entorno hostil en planos generales del paisaje abrupto - los montes y la laguna - y pobre - la tierra áspera y baldía-, densifican ese espesor atmosférico, plagado además de continuas alusiones al profético advenimiento del escarmiento (las auricularizaciones del espíritu paterno, el feroz embate de los elementos climatológicos...) y donde la masa popular compuesta por los lugareños de la zona adopta, con sus continuas acusaciones y sus frecuentes miradas inquisitivas y reprobatorias, la función de un coro trágico sobre el que destacan las figuras del buhonero que descubre el suceso (Félix Fernández) y de la vieja criada Rosario (Irene Caba Alba); el primero proveniente de La tierra de Alvargonzález pero mucho más desarrollado en La laguna negra, mientras que la segunda es una creación original de la película. Ambos elementos sobresalen del paisanaje como modelos singulares de esa función amenazante que concierne a la masa popular, correspondiendo además cada uno de ellos a los dos espacios de la acción: él al paisaje exterior (su condición de vulgar mercachifle y su carácter errante lo convierten en paradigma del alma popular que vaga por las tierras castellanas) y ella al interior del caserón labriego (congregando la parcela más intimista de la tradición, con su sabiduría ancestral y su firme sujeción a los arraigados ritos cristianos).

Pero es en las porciones del discurso dedicadas al regreso de Miguel al pueblo coincidiendo con las celebraciones de la festividad patronal cuando la pátina costumbrista resulta más perceptible mediante un largo fragmento que mixtura secuencias relativas al progreso de los acontecimientos (la llegada del indiano, el encuentro con sus hermanos y sus primeras sospechas sobre la extraña muerte del padre) con imágenes ajenas al propio relato y centradas en la exposición de los diversos actos lúdicos y profanos que componen los festejos (la romería, el espectáculo de la becerrada, las bandas de música, las danzas tradicionales...). Lo más interesante es que ambas vertientes - la narrativa y la descriptivaacaban confluyendo con la exposición del propio romance de La laguna negra en la plaza principal del pueblo ante la expectación de los lugareños y la conmoción de Miguel, comenzando éste a tomar así conciencia de las atroces conductas de sus hermanos. El desarrollo argumental de la trama se anuda de este modo con esa deleitación discursiva en la cultura popular en directas remisiones a la urdimbre machadiana. 
Si, como habíamos dicho, el propósito esencial de Machado no era otro que crear un nuevo romancero que emanase del $-\mathrm{y}$ se dirigiese alpueblo, abrevando en esa "expresión perfecta del gusto popular" (García Mateos, 1990: 413) que representan los pliegos de cordel, el discurso fílmico parece ir más allá, desplegando en el punto crucial de la trama perspicaces dispositivos de mise en abyme hacia los supuestos orígenes de la leyenda vulgar, incidiendo así el relato en la insinuación — lúdica y reflexiva- de la fingida veracidad de los hechos representados en el romance y en el filme; insinuación que además parece ser corroborada por el último plano de la película, consistente en un movimiento panorámico desde el gran plano general de La laguna negra hasta las escarpadas cumbres que la jalonan, sobre las cuales se divisa la silueta del mercader ambulante y su perro Caifás. Augur pedestre de la tragedia y trovador errante de Castilla, la figura del buhonero se pierde en lontananza tal vez con el propósito de cantar nuevas desdichas o de propagar el propio romance de La laguna negra.

\subsection{Cosmogonía y regeneracionismo}

Junto a toda esta nutrida gama de invocaciones de la "atmósfera sobrenatural obsesiva" (Panizo, 1986: 216) del relato machadiano, el discurso va desplegando la imposición del castigo, dilatando la línea mítica y la dimensión telúrica a través de una carga simbólica asociada a la corporeidad del paisaje, a modo de voraz masa orgánica sustentada sobre los elementos, en íntima e indisociable relación con el padecimiento de los personajes que lo habitan. La fusión de la tierra con los vestigios de la civilización asentada sobre ella parece insinuarse ya en ciertos fragmentos en los que la fotografía y la iluminación impresionista otorgan una singular plasticidad retratando las edificaciones humanas como prolongación del paisaje, pero se hace patente con la correlación de la profecía del padre acerca de la aridez de esa tierra maldita ("La tierra se hará polvo seco en vuestras manos. Entrará la plaga en el redil y en las paneras") con la infecundidad de la mujer ("No tendréis hijos que os hereden después de daros ternura y obediencia") ${ }^{6}$. Pero también el aire (los vientos que

${ }^{6}$ En un recurso muy habitual del drama rural, al tiempo que la tierra se vuelve yerma por estar maldita, también las mujeres de la familia resultan estériles. Si Candelas ya lo es desde el comienzo, 
difunden la voz espectral del padre), el fuego (el personaje de Candelas, la lumbre del hogar y especialmente la dantesca secuencia del incendio), y sobre todo el agua (en diversas formas: la laguna como foco del cainismo y el parricidio - "el horror de mi sangre en esta laguna negra" - , las nubes negras que presagian tormenta y la lluvia torrencial) adquieren como elementos igualmente malditos una progresiva presencia como indicio del sino fatídico de los vástagos criminales. Inserta la semilla del caos en las fuentes del Duero, el río que atraviesa la meseta regando sus campos y propagando la muerte y el mal sobre la esencia castellana — española-, la ira de los elementos se desata contra una tierra degenerada. El discurso de la culpa, la conciencia y el castigo se desarrolla así en una estampa cruda y grotesca que conecta por vía directa con la crítica visión noventayochista de la obra literaria de partida.

Un mínimo, pero revelador hálito optimista, se desprende no obstante del desenlace positivo de la sucinta subtrama esbozada en torno a los personajes de Miguel y Ángela; un confuso bosquejo melodramático - apenas insinuado acerca de posibles destellos de un amor pasado- pero fundamental por cuanto concluirá con la salvación de ambos —únicos personajes inocentes del cuadro protagónico de la tragedia-, despuntando sobre el mortífero castigo de la familia y de sus tierras. Asimismo, el retorno de Miguel supone además una palmaria prolongación de la intensa red alegórica, al presentarse como el hijo pródigo, o más certeramente como la resurrección terrenal de la deidad asesinada, dispuesto a acatar los designios del Padre, difundiendo su palabra entre sus hermanos pecadores. De hecho, si ya su propio nombre - Miguel, literalmente en hebreo antiguo: quién [m] como [k] Dios [El] (García Gallarín, 1998: 232)— parece dar continuidad a la simbología antroponímica desplegada en el relato (Ángela, Candelas, Rosario, Caifás...), dos concisas frases del diálogo apuntalan esa dimensión figurativa del personaje como reencarnación del espíritu paterno ("No escandalices mujer, que no soy ningún resucitado", le dice a Candelas cuando ésta percibe su aparición como un milagro) y consiguiente personificación del aura divina del Padre ("Te necesito para que me digas, como si hablaras con dios [quién como Dios], cuál es la verdad de lo que le pasó al padre", le dice a la devota Ángela). Así, su aparición durante la única digresión jubilosa del lúgubre discurso y su indumentaria elegante,

también Ángela perderá el hijo que espera de Juan. 
diáfana y moderna, en contraste con los ropajes fúnebres e inveterados del luto familiar, remarcan su carácter ajeno y antagónico a la mezquindad y la miseria que padecen sus hermanos.

Desde esta perspectiva, la salvación final de Miguel - recto en su comportamiento, fiel al apego paterno y exento de castigo- y Ángela —una vez redimidos sus pecados, abortada la simiente maligna que llevaba en sus entrañas - representa el mensaje de esperanza que se acaba imponiendo a la abominable visión de una tierra maldita. Es así como el filme se acopia de la vertiente regeneracionista de la línea crítica de Machado mediante la figura del indiano, apartado de su patria, pero que vuelve del exilio para abatir a los fratricidas sublevados. De hecho, pese a que un visionado muy superficial podría derivar en apresuradas consideraciones sobre la concordancia de la moralidad católica que parece desprenderse del desenlace - la imposición de la justicia divina, con su castigo ejemplar a los pecadores - con las coordenadas ideológicas de su contexto de realización, en realidad dicha resolución súbita y simple (el fallecimiento de todos los malhechores, Candelas, Juan y Martín, asesinándose entre sí, y la esperanza subyacente tras la victoria de los inocentes, Miguel y Ángela) cabría vincularla más directamente a esos patrones míticos como solución deus ex máchina de una tragedia dotada de una amplia gama de referencias religiosas que operan como remisiones a un sustrato cultural de supersticiones y creencias ancestrales, en un relato que reposa y se compendia en la parábola sintetizada por ese breviario argumental del sermón paterno. El andamiaje bíblico - del Génesis al Apocalipsis - y el ornamento litúrgico se mixturan con la sustancia mitológica pagana, incorporando además sutiles referencias a la tragedia clásica en un relato que hunde sus raíces en el mito - lo universal y lo eterno humano - pero para acabar germinando en la tradición castellana hasta alzar la voz lírica machadiana - institucionista, noventayochistasobre el presente contextual al filme, donde la cuestión cainita seguía teniendo una lamentable actualidad. La desolada representación de una tierra degradada por los macabros actos de sus diabólicas criaturas, con el específico epicentro castellano como reflejo del conjunto español, conecta así la óptica machadiana con la amarga mirada de un cineasta cuya trayectoria estuvo igualmente condicionada por los terribles avatares que habían sacudido violentamente a la sociedad española de su tiempo. En este sentido, si Martínez Menchén afirmaba acerca de la poesía de 
Antonio Machado que la "sombra de Caín es una de sus obsesiones", preguntándose "¿cómo no iba a serlo para un hombre del 98, para un hombre que ha visto los últimos años de la historia de su patria como una grotesca e ininterrumpida sucesión de luchas civiles?" (1976: 1002), lo mismo podría decirse de Arturo Ruiz-Castillo y de una película realizada poco más de una década después de la Guerra Civil española.

\section{DOS CAMINOS, DOS VIDAS... DOS ESPAÑAS}

Volviendo a Dos caminos, el título de la película encierra en sí mismo un sustancial indicio de la prolongación de la estela machadiana al adoptar uno de sus temas de mayor calado poético, la idea del camino en su más amplia acepción dual "como lugar físico por donde se pasa, pero también el propio pasar” (Merchán Alcalá, 2004: 277), lo cual resulta especialmente esclarecido desde el mismo arranque de la obra con la sucesión de los títulos de crédito sobre la imagen estática de una calzada empedrada que después entra en movimiento en travelling cenital, acompañando los pasos de los guerrilleros que en la primera secuencia de la película se disponen a capturar a Antonio (Ángel Picazo) —el republicano que se había quedado en España, adaptándose a la sociedad posbélica-, separándolo de su familia para conducirlo junto a Miguel —el republicano que había persistido en su lucha desde el exilio- - De este modo, el título y el plano inicial aluden ya a esa doble dimensión del camino, la espiritual (el camino como existencia: Dos caminos o dos modos de vivir) y la material (la superficie pisada al caminar: el sendero pedregoso por el que transitan dichas vidas). Pero, además, el procedimiento es ciertamente similar al efectuado en La laguna negra, dado que en ambas películas los créditos se presentan sobre la diégesis con una imagen inicialmente congelada que luego marcará el comienzo discursivo y que parece contener toda una declaración de intenciones. Inscribiéndose la alegoría machadiana en dichos planos inaugurales, el bodegón costumbrista de la tierra cainita castellana y el camino se antojan pues como las ilustraciones esenciales de los dos pliegues del díptico.

Tras la irrupción de una voice over que ubica el lugar y momento exacto de la acción ${ }^{7}$, los dos amigos vuelven a encontrarse al necesitar Miguel

7 “Después de la Segunda Guerra Mundial, en el otoño de 1945, la frontera española de los Pirineos 
- herido de gravedad - los servicios del médico Antonio, comenzando una discusión acerca de sus diferentes posturas ante la derrota que deriva en una descripción de los rumbos opuestos emprendidos tras su separación. El relato se estructura entonces mediante dos grandes analepsis en la que los dos antiguos combatientes se cuentan el uno al otro sus vidas, las cuales simbolizan los dos caminos posibles transitados por los demócratas vencidos - la sumisión y el destierro - y que al mismo tiempo permiten al discurso establecer una mirada a las dos Españas posbélicas - la de la sociedad española de la dictadura y la de los estertores republicanos en el exilio-, ambas además desde el punto de vista de los derrotados.

\subsection{España que ora y bosteza. La sociedad posbélica}

Tras unos planos que evocan el final de la Guerra Civil, la acción comienza con la voz en off de Antonio ("Estábamos derrotados. Ya no éramos un ejército, ni siquiera personas. El miedo era contagioso y estúpido. Todos íbamos pensando en nuestro propio problema...") sobre las imágenes de la desbandada republicana hacia el exilio francés, alternándose planos del camión en el que viajan los personajes principales, Antonio y Miguel, con sobrecogedores planos generales de la diáspora que describen el éxodo de cientos de personas - milicianos y civiles, vencidos y heridosaproximándose en tropel hacia la frontera pirenaica. Es entonces cuando se produce la bifurcación de los caminos de los protagonistas al decidir Antonio saltar del camión en una arriesgada decisión que él mismo explica como el profético temor de no volver nunca a su tierra ("De pronto tuve la evidencia de que aquella tierra que quedaba a nuestras espaldas se alejaba para muchos meses, acaso para muchos años, quizá para toda la vida... Aquello todavía era lo nuestro, España, y había que quedarse pasara lo que pasara").

Una elipsis conduce inmediatamente a la imagen del personaje siendo rehabilitado para volver a ocupar su plaza anterior a la contienda como médico de pueblo; el mismo oficio y en el mismo lugar. Así lo manifiesta el alcalde y doctor principal de la localidad don Tomás (Luis

vio volver en plan de guerra a unos hombres que seis años antes habían huido derrotados. Fue entonces cuando dos españoles que antes tomaron caminos distintos volvieron a encontrarse. Dos vidas, que habían sido tan opuestas como lo son la verdad y la mentira, se fundieron sobre una tierra que había sabido esperarles"). 
Pérez de León) en el momento del regreso ("Ya estamos juntos otra vez. Como si no hubiera pasado nada"), advirtiendo no obstante de las adversidades a las que tendrá que hacer frente ("Ha habido sus más y sus menos. Ya verás, ya verás..."). Y en efecto, si ya desde su llegada el propio republicano confiesa en voz en off sus temores, introduciendo asimismo sus posibles cargos de conciencia ("Nunca pensé que regresar al pueblo me produjera aquella sensación de miedo y culpabilidad. Lo leía en los ojos de la gente") en unos planos que al mismo tiempo parecen evocar las consecuencias de la guerra (mostrando la abundancia de mujeres vestidas de luto y predominando entre las figuras masculinas individuos de edad avanzada y sobre todo niños frente a la escasez de varones coetáneos al protagonista), las hostilidades pronto comienzan a manifestarse, primeramente con el comentario satírico del alguacil Cipriano (Manuel Guitián) cuando el alcalde solicita su ayuda para trasladar el equipaje de Antonio ("Señor alcalde, a esto le llamaban antes la explotación del hombre por el hombre"), prosiguiendo con la negativa de una mujer viuda ante la petición de alojamiento en su posada ("Desde que me mataron al marido los huéspedes los elijo yo") y desembocando en el escarnio público efectuado por el propio Cipriano al pregonar el regreso del republicano como médico del barrio bajo ("Ya estáis avisados, que éste es de los que matan con medicinas y con discursos y mítines y demonios encendidos").

En cualquier caso, los fragmentos más trascendentales del relato corresponden a la presentación de la dicotomía entre Antonio y don Tomás (obviamente, representantes de los dos bandos de la contienda) en dos secuencias en las que sus enfrentamientos dialécticos son acentuados por un calculado trabajo de encuadre, angulación y montaje que enfatiza la evolución del republicano desafiando la superioridad del alcalde (especialmente perceptible en el primero de los fragmentos: planocontraplano inicial confrontando los estatus de ambos personajes, opresor / oprimido; breve plano secuencia central ilustrando el avance desafiante de Antonio hacia don Tomás; plano-contraplano final vaticinando el preludio de la conciliación pero confirmando también el progreso del republicano en contrapicado) al tiempo que una sutil pero muy significativa urdimbre metafórica (establecida por determinados elementos de atrezo, como el pájaro enjaulado destacado en primer término del encuadre o la creciente presencia de motivos cinegéticos - una cabeza de venado expuesta en la pared y varias presas disecadas sobre la mesa - que subrayan las 
distracciones del alcalde apuntando involuntariamente con su escopeta hacia el torso del republicano mientras ironiza "...pierde cuidado, soy cazador viejo") denuncia la situación de Antonio, cercado por esa opresiva sociedad posbélica acaudillada por don Tomás. Solo con la ejecución de sus actos redentores mediante la aplicación de su oficio (primero salvando la vida de un niño gravemente enfermo al que el médico-alcalde se había negado a atender por estar ocupado practicando la caza, y después operando de urgencia al propio don Tomás cuando éste se autolesiona con el disparo accidental de su escopeta) demostrado su voluntad de auxiliar al pueblo y al poder, el republicano logra ser aceptado. Un sumario compuesto por el montaje de tres planos confirma dicha reinserción social consumada por medio de su enlace matrimonial con la sobrina del alcalde (María Luisa Abad): plano general de las campanas mientras la partitura se funde con los reconocibles acordes nupciales; plano detalle de la inserción del anillo; plano del hijo del matrimonio que augura la prosperidad, dando comienzo a la última secuencia de la analepsis que muestra la placentera vida familiar.

Como vemos, no titubea el discurso al describir una sociedad hostil y desconfiada, deprimida y sumida en un constante estado de duelo donde las huellas de la muerte y el sentimiento de la ausencia evocan las consecuencias bélicas - , empobrecida, injusta y fuertemente jerarquizada - radicalmente polarizada, sin estratos intermedios, entre la opulencia de la autoridad y la miseria del barrio bajo - y acaudillada por un ser déspota y autoritario - que congrega de modo unitario todos los poderes, legales y fácticos-, más interesado en saciar sus apetitos ociosos que en velar por la salud y el bienestar de su pueblo, y cuya perversidad parece sugerirse en el goce que halla al observar el sufrimiento de su recluso, figurativamente enjaulado y a punta de escopeta. Asimismo, la profunda oposición que se realiza entre la moral de don Tomás — médico viejo, que nunca ejerce su oficio y metafóricamente circundado por múltiples símbolos de caza-y de Antonio - médico nuevo, que asume las responsabilidades sanitarias del desertor y que ante la mencionada ausencia masculina parece ser el único capaz de engendrar vida - sugiere en definitiva el enfrentamiento entre el mal y el bien, la muerte y la vida. Pero, si pese a todo lo dicho todavía se podría percibir el desenlace del relato como la sumisión del republicano a la sociedad posbélica - y, por tanto, el sometimiento del derrotado al credo victorioso de la guerra - una última imagen de apariencia anodina resulta en cambio altamente esclarecedora. El plano final del sumario (que sirve al 
mismo tiempo de imagen inicial de la secuencia que clausura el flashback, relativa a la entrada de los guerrilleros que irrumpen en la armoniosa estampa familiar para secuestrar a Antonio, conectando con el comienzo del relato) muestra al hijo de Antonio y la sobrina de don Tomás en la estancia anteriormente destinada al despacho del alcalde, manipulando un cañón de juguete que acciona para disparar contra el personaje que entra en la habitación, el propio alcalde don Tomás, quien mitiga su sobresalto con una ironía ("Ten cuidado que el diablo las gasta muy malas. No vayas a dar a tu padre trabajo otra vez"), ante la astuta sonrisa del padre del niño. De este modo, la plácida vida conyugal - elemento consumador de la conciliación - se inicia con un acto instantáneo, de aspecto inocuo y hasta festivo, pero que esconde en realidad el síntoma mordaz de la pervivencia de la confrontación, latente en Antonio pero que brota en su hijo como beligerante semilla de la rebelión. Descendiente de vencedores y vencidos, el niño gestado en la sociedad surgida de las cenizas de la guerra (ese español que quiere / vivir y a vivir empieza, / entre una España que muere / y otra España que bosteza) es en sí mismo la abismal fractura de las dos Españas, punzante, perpetua y todavía más honda tras la contienda.

\subsection{España del cincel y de la maza. El exilio}

Concluido el primer flashback, el grueso del relato lo conforma el periplo vital de Miguel, desarrollado en torno a dos hilos conductores, uno de ellos de corte melodramático constituido por su historia romántica con Marcelle (María Asquerino) — una joven francesa a quien conoce al poco de cruzar la frontera cuando se refugia en su casa tratando de evitar su confinamiento en un campo de concentración - y determinado el otro por sus anhelos de regreso a España. El amor y la tierra se establecen entonces como resortes argumentales de la historia del exiliado, narrada por medio de grandes elipsis y abundantes irrupciones de su voz en off con el objeto de cohesionar los diversos bloques de acción en que se divide su odisea. El hecho de que los progresos de la trama se correspondan con decisivos episodios del contexto político internacional, convierte además al personaje en vehículo idóneo para esbozar una amplia visión de algunos de los acontecimientos más relevantes y dramáticos de la Historia contemporánea. Tras iniciarse su relato en el pueblo fronterizo de Le Perthus, formando parte de la gran diáspora republicana, su situación 
se complica por matar a un gendarme senegalés - que previamente había asesinado a su amigo Pedro- durante su reclusión en el campo de Argelès, lo que le obliga a huir, teniendo que abandonar a Marcelle. Prófugo de la justicia y refugiado en un puerto industrial donde trata de pasar inadvertido, pronto es interceptado por el Socorro Rojo Internacional, organismo para el que debe trabajar ante el estallido de la Segunda Guerra Mundial y la invasión alemana de Francia. La muerte de Marcelle en un bombardeo tras el reencuentro de los amantes y el recrudecimiento de la guerra ante el empuje aliado, le conducen finalmente a internarse en el maquis como medio desesperado para regresar a su hogar.

Del mismo modo que en el primer relato se ofrecía una representación subrepticia de la cruda sociedad franquista, el discurso tampoco esquiva la descripción peyorativa del exilio, destacando las injusticias y la opresión agudizadas por el confuso y vacilante panorama internacional. Si ya desde el mismo momento del éxodo se deja constancia de la desigualdad de trato a la que son sometidos los individuos al ser divididos en función de su documentación, es en los fragmentos del campo de internamiento donde se incide en esa confrontación republicana en una secuencia que muestra la indignación de los reclusos Miguel y Pedro ante el autoritarismo del comandante español (José Nieto) que colabora con los mandos franceses. Las mayores evidencias se alcanzarán no obstante con la persecución y coacción que sufre el protagonista por parte de los miembros del Partido Comunista y del Socorro Rojo Internacional y la basculante conducta de algunos grupos de exiliados durante la ocupación alemana. Pero, contrastando con esa atmósfera perniciosa, paralelamente el discurso presenta una llamativa dignificación del personaje principal siguiendo la misma línea de lo ocurrido con el personaje de Antonio. A pesar de que algunas aproximaciones críticas al filme han tendido a detectar la tradicional caricaturización del guerrillero como símbolo del $\mathrm{mal}^{8}$, si ya en los diálogos entre Miguel y Antonio se dan ciertos indicios de un comportamiento indulgente ${ }^{9}$, es en la secuencia de la despedida entre

\footnotetext{
${ }^{8}$ Así parece opinar por ejemplo Moreno-Nuño al declarar: "Miguel is represented as a criminal due to his morals: egoism, resentment, and violence" (2012: 89).

${ }^{9}$ Pues ya al comienzo de la película la primera preocupación de Miguel tras haber ordenado la captura de Antonio es conocer el trato recibido (“¿Te trataron bien mis hombres?”); y, del mismo modo, hacia el final del relato Miguel reconoce haber provocado el secuestro de Antonio para no perjudicarle, ya que un encuentro de carácter más pacífico podría haber implicado al médico en la
} 
Miguel y Marcelle cuando la dignidad del exiliado parece resultar más palmaria. Tras haberse fugado del campo de concentración por el asesinato del gendarme, Miguel acude atormentado a casa de Marcelle confesándole lo sucedido (en francés, acaso atenuando la alusión a un crimen innombrable: "J 'ai tué un homme"), tratando de justificar su acto ("No pude evitarlo, Marcelle, había matado a mi amigo") y manifestando después su preocupación por su incierto destino al ser perseguido por la justicia francesa, no pudiendo tampoco volver a España por las consecuencias de la guerra. Confusa, Marcelle pregunta entonces si la justicia española también le persigue por las mismas razones; instante en que un travelling aproxima el rostro de Miguel, aislándolo del plano conjunto, mientras responde sorprendido por las dudas de Marcelle: “¿Yo? No. En la guerra se disparan tiros y nadie saben dónde van, pero eso... no". Finalmente, ante su complicada situación, Miguel decide abandonar a Marcelle para no comprometerla. Pero esa voluntad altruista del exiliado que antepone la seguridad de la muchacha a su propio beneficio y que parece rehuir la violencia explícita aterrado por sus propios actos criminales, se completa además con una manifiesta dimensión de víctima — expatriado de su tierra, perseguido por la justicia, acorralado por sus propios correligionariosque derivará incluso en su caracterización como mártir, cuando, consciente de su fracaso, comience a abandonar sus propósitos iniciales para aferrarse al único anhelo de regresar a su tierra solo para morir.

Retomando la secuencia central del filme con la que comenzábamos el presente estudio - ubicada, recordemos, en el punto intermedio del discurso-, los versos finales de Orillas del Duero parecían provocar una honda conmoción en el espíritu del protagonista, despertando su más brioso anhelo por la tierra perdida pero atemorizándole también ante la posibilidad de no volver nunca a ella ${ }^{10}$. En este sentido, la inmediata muerte de su amigo Pedro (que, tras haber presenciado el fallecimiento del poeta, musitaba en presencia de Miguel sus últimas palabras: "Mala suerte, morir aquí. Lejos de España, en esta tierra... lejos... lejos”) constituye el contrapunto definitivo de la amenaza del no retorno. De este modo, si a lo largo de nuestro discurso venimos argumentando que la figurativa

\footnotetext{
causa del guerrillero ("Te he hecho el favor de traerte por las malas").

${ }^{10}$ Como afirma Martínez Álvarez, "Ruiz Castillo utilizó la nostalgia evocada por Machado, homenajeándolo en su destierro, para convertir su verso en el desiderátum del guerrillero: volver" (Martínez Álvarez, 2012: 228).
} 
muerte de Machado en el filme desborda con mucho la mera anécdota, podrá comprenderse ahora que dicha secuencia se erige, nada más y nada menos, que en la metáfora del fracaso republicano y del temor a la muerte en el exilio. Es más, hasta tal punto parecen calar en Miguel los versos machadianos y su posterior muerte - la conciencia de la derrota republicana y el miedo a no volver jamás - que la misma muerte podría leerse incluso como una alegoría de la transfiguración, de tal modo que a partir de entonces Miguel comenzará a desistir de sus propósitos para iniciar la andadura de su camino, que, en el sentido más poético, es el camino soñado por el poeta en busca de lo añorado - la tierra, que por momentos identificará con el amor en la imagen de una mujer que acabará perdiendo - ; un camino, en definitiva, hacia la muerte.

La ya referida secuencia de la despedida de Marcelle resulta sumamente esclarecedora de cuanto decimos. Justo en el instante en que la habíamos dejado — con el travelling hacia el rostro de Miguel—una sucesión de primeros planos de Marcelle y Miguel presentan el diálogo de los personajes, incitando la mujer el regreso a España, a lo que Miguel responde con el verso “¡hermosa tierra de España!”, y añadiendo después: "No puedo volver. No puedo. No volveré más que..." Tras la premonición de la muerte, unos primerísimos primeros planos consuman el proceso de aproximación intimista efectuado en el fragmento para concluir con las palabras de Miguel que identifican a la mujer con su añoranza de la tierra: "Me persiguen, me pueden matar mañana, tal vez esta misma noche y no tengo más tierra ni más cielo que tú".

Tiempo después, hacia el final del flashback, el fallecimiento de Marcelle será el síntoma final de la soledad de Miguel. Fracasado, falto de ideales y de amor, pero respondiendo a la vivificación del sueño del poeta, parece que ya solo resta un paso en su camino: regresar para morir.

\section{CODA. UN TROZO DE PLANETA POR DONDE CRUZA ERRANTE LA SOMBRA DE CAÍN}

La secuencia final de Dos caminos muestra a Miguel y Antonio en los momentos posteriores a sus respectivas rememoraciones. Los compañeros de la guerrilla antifranquista comunican a Miguel la desesperada situación: están cercados sin escapatoria y urge la rendición o la huida a Francia. Tras exclamar "He huido una vez, pero ahora no. He venido a España 
para quedarme en esta tierra de una forma o de otra", el protagonista procede entonces a su propio sacrificio saliendo de la cueva en la que estaba refugiado para ser acribillado por la metralla de la Guardia Civil. A continuación, un plano detalle de su mano rasgando la tierra conduce en lenta panorámica al primer plano de su rostro alzando la vista al cielo, y expresando después en un siguiente plano "la tierra... volver", justo antes de fallecer mientras un coro solemne ejecuta los últimos acordes de la partitura del filme.

Pese a que el final de la película ha sido percibido en no pocas ocasiones como la constatación de la supuesta sumisión de la obra a la corriente de adoctrinamiento ideológico del Régimen, consideramos que dichas imágenes se hallan en perfecta sintonía con el desarrollo de un discurso reflexivo y juicioso, donde la ácida y reprobatoria consideración de las dos Españas posbélicas (de la República exiliada — de modo patente - y de la Dictadura imperante — lógicamente, más críptica-) es el contrapunto para la exaltación humana de sus víctimas, los demócratas derrotados, cuyos dos caminos no son otros que la muerte y la supervivencia; todo ello además sirviendo de contundente colofón a la bilogía machadiana.

Consumando el impulso mesiánico que había guiado su espíritu desde el crucial encuentro de Argelès donde expiraban agonizantes los últimos ecos de la República, y asiendo el anhelado polvo de una tierra devastada (tierra, más que nunca, por donde cruza errante la sombra de Caín, a la que Antonio Machado había cantado en Campos de Castilla y que Arturo Ruiz-Castillo había filmado en La laguna negra), aferrándose a su tierra al fin y al cabo, Miguel — trasunto andante, estela onírica, del camino soñado por el poeta yerto-, alza la mirada al cielo para, en el final de su camino, ver el sol ("sol del día... claro día... ¡hermosa tierra de España!"). De nuevo Miguel, de nuevo el exiliado transfigurado — quien como Dios - en una difunta deidad figurativa (el Padre, Alvargonzález; el poeta, Antonio Machado), vuelve a su patria brutalmente herida, tan anegada de sangre y horror, sea para redimirla, sea para morir en ella.

\section{REFERENCIAS BIBLIOGRÁFICAS}

AlVAR, M. (1997). Antonio Machado. Poesías completas. Madrid: 
Espasa Calpe.

BECEIRO, C. (1975). "Semántica y semiótica del sueño en Antonio Machado". Archivum: Revista de la Facultad de Filología 25, 85117.

(1994). "Las versiones de La tierra de Alvargonzález, de Antonio Machado". Revista de Literatura 112, 417-436.

(2000). "Una alerta para la crítica: La debatida cuestión en La tierra de Alvargonzález". Moenia 6, 373-376.

CASTRO DE PAZ, J. L. (2002). Un cinema herido. Los turbios años cuarenta en el cine español (1939-1950). Barcelona: Paidós.

(2012). Sombras desoladas. Costumbrismo, humor, melancolía y reflexividad en el cine español de los años cuarenta. Santander: Shangrila.

CEREZO GALÁN, P. (1975). Palabra en el tiempo. Poesía y filosofía de Antonio Machado. Madrid: Gredos.

DÍAZ, L. (1954). "Dos caminos. Un film sobre el problema de los emigrados políticos". Cuadernos de Cultura 16, 16-17.

DÍEZ PUERTAS, E. (2003). Historia social del cine en España. Madrid: Fundamentos.

GARCÍA GALLARÍN, C. (1998). Los nombres propios de pila españoles. Madrid: Ediciones del Prado.

GARCÍA MATEOS, R. (1990). "La poesía de tradición oral y la obra de Antonio Machado". En Antonio Machado hoy. Actas del Congreso Internacional del cincuentenario del fallecimiento de Antonio Machado, VV.AA., vol. I, 405-418. Sevilla: Alfar.

GIBSON. I. (2006). Ligero de equipaje. La vida de Antonio Machado. Madrid: Santillana.

GÓMEZ BECEIRO, F. (2016). "Las raíces culturales de un cineasta olvidado. Aproximación a la trayectoria artística de Arturo RuizCastillo durante la Segunda República”. En Faros y torres vigía: el cine español durante la Segunda República, J. Pérez Perucha y A. Rubio Alcover (eds.), 205-226. A Coruña: Vía Láctea, AEHC. GONZÁLEZ, A. (1986). Antonio Machado. Madrid: Ediciones Júcar. JIMÉNEZ-LANDI, A. (1993). "La Institución Libre de Enseñanza en la vida y en la obra de Antonio Machado". En Antonio Machado hacia Europa, P. L. Ávila (dir.), 263-271. Madrid: Visor Libros.

MACHADO, A. (1999a). Antología comentada. V. I. Poesía, F. Caudet 
(ed.). Madrid: Ediciones de la Torre.

(1999b). Antología comentada. V. II. Prosa, F. Caudet (ed.). Madrid: Ediciones de la Torre.

MARTÍNEZ ÁLVAREZ, J. (2012). "Las películas sobre el maquis español: de la historia oficial a la memoria histórica". Cuadernos de Historia Contemporánea 34, 225-250.

MARTÍNEZ MENCHÉN, A. (1976) "La tierra de Alvargonzález en la poética de Antonio Machado". Cuadernos hispanoamericanos 304-307, t. II, 986-1004.

MERCHÁN ALCALÁ, J. (2004). Un canto en la frontera. La lógica poética de Antonio Machado. Tesis Doctoral. Almería: Universidad de Almería.

MORENO-NUÑO, C. (2012). “Criminalizing Maquis: Configurations of Anti-Francoist Guerrilla Fighters as Bandoleros and Bandits in Cultural Discourse". HIOL: Hispanic Issues On Line 10, 7999, https://cla.umn.edu/hispanic-issues/online/volume-10-armedresistance [21/03/2019].

PANIZO, J. (1986). "Anotaciones al romance La Tierra de Alvargonzález". Revista de Folklore 72, 212-216.

RIVA, S. (2009). “'Avena loca y cizaña': Ideología y tradición popular en la poesía de Antonio Machado". En Lo vivo lejano. Poéticas españolas en diálogo con la tradición, M. Romano (coord.), 41-56. Mar de Plata (Argentina): EUDEM.

RUIZ-CASTILLO, A. (s.f.). Manuscrito autobiográfico inédito. Madrid: Residencia de Estudiantes (Centro de Documentación).

(1952). La laguna negra [Película]. Madrid: Suevia Films - Cesáreo González [Productora]. Copia disponible en Filmoteca Española. (1953). Dos caminos [Película]. Madrid: Eos Films [Productora]. Copia disponible en Filmoteca Española.

TORRES LÓPEZ, C. (1990). “El tema del 'camino' en la poesía de Antonio Machado". En Antonio Machado hoy. Actas del Congreso Internacional del cincuentenario del fallecimiento de Antonio Machado, VV.AA., vol. I, 513-528. Sevilla: Alfar.

VILA-BELDA, R. (2006). "La visión institucionista del paisaje en Antonio Machado". En Hoy es siempre todavía. Curso internacional sobre Antonio Machado, J. Doménech (coord.), 198-229. Sevilla: Renacimiento, Ayuntamiento de Córdoba. 
ZUNZUNEGUI, S. (2002). Historias de España. De qué hablamos cuando hablamos de cine español. Valencia: Ediciones de la Filmoteca.

Recibido el 19 de enero de 2020.

Aceptado el 20 de abril de 2020. 